THURSDAY, SEPTEMBER 9, I875

\section{THE SCIENCE COMMISSION REPORT} THE ADVANCEMENT OF SCIENCE*

$O N$

TNDER head III. is brought forward the "Evidence relating to the Establishment of Physical Observatories."

On the general question of the establishment and maintenance of Physical Observatories, Lord Salisbury agrees that-

". . . Some of these institutions which have been alluded to in your grace's question, especially observatories, clearly fall within the duties of the Government; and certainly, from all that one hears, it is probable that their duty in that respect is inadequately performed, and that observatories for a much larger range of observations might with great advantage be multiplied." . . . .

Sir George Airy, Astronomer Royal, thus states his view on the subject:-

"When I began to be an astronomer, such questions as those of the constitution of the sun and the like were not entertained."

"Are you prepared to express an opinion as to whether it is an object which would be a proper one for the Government to take up as a State Establishment ?-The Government are already pushed very hard in their estimates. The screw is always put upon them, 'Cannot you reduce the estimates a little more?' And then it would always come to a question of extensive feeling in the Hiouse of Commons, and of popular feeling out of the House of Commons; and I am confident from what I have seen that those two bodies would not in every case support an extension."

"Should you say that it is an object which is not very likely to be prosecuted with sufficient vigour unless taken up by the Government ? -I do not see how it could go on except it were taken up by the Government. I do not believe that it could go on in any other way."

"It is not likely, you think, to be prosecuted by private individuals, or by other public bodies such as the Universities?-No, I think that their funds are almost all required for other objects, and the difficulty even of getting the business into shape is extremely great." . . . .

"Then such observations, in all probability, will either not be made at all or must be taken up by the Government?-That is my view." . . . .

Mr. De la Rue's opinion is thus given in reply to question 13,066 :-

"I think that the time for the State providing means for reducing observations has now come : when the State should take up, besides mathematical astronomy (which deals with the places of the stars and planets, and the moon especially), physical observations, more particularly observations of the sun, which appear to me to bear directly upon meteorological phenomena." . . . .

Sir W. Thomson points out the importance of multiplying such Observatories :-

". . . In respect to the observatories, it might be necessary to have several observatories for astronomical physics in this country, if it were only to secure observations of interesting conjunctures, notwithstanding the varieties of the weather, that there may be in different parts of the country ; and, again, observatories for astronomical physics ought most certainly to be founded in other parts of the British dominions than England, Ireland, and Scotland; in other latitudes and on the other side of the world."

VoL. $x$ xx, -No. 306
Dr. Siemens expresses the same view in the following evidence :-

". . . An observatory or several observatories should be established for carrying on physical research, research to obtain information on general subjects, such as solar observations, magnetic observations, and other subjects that might be thought desirable to obtain continually information upon."

"I think that almost the only new establishments which you recommend are certain physical observatories? -Yes."

"What would be the principal object of such observatories?-For the purpose of magnetic observations, solar observations, and other general inquiries into physical phenomena."

"Do you contemplate the establishment of more than one such observatory?-Probably more than one would be desirable."

"Do you contemplate the establishment of any such observatories in any of the colonial possessions of the country ?-Yes, I think so."

"Speaking generally, would they be costly establishments to found? - Not very costly, not so costly as astronomical observatories."

Dr. Frankland has also given evidence on the impor. tance of promoting the study of Astronomical Physics, pointing out that "it would be necessary, in connection with the Physico-Astronomical Observatory, to have the means of performing various chemical experiments and making physical observations. Of course the chemica1 operations would be quite subsidiary to the cosmical observations there."

Mr. De la Rue, in reference to locality and organisation, in answer to the question whether provision for carrying out observations of this character should be in connection with the Greenwich Observatory, says :-

"In connection with the Greenwich Observatory, yes, but at the Greenwich Observatory, I should say not. I do not think, in the first place, that there is space enough at Greenwich, and the duties of the staff are already so very onerous that it would require a separate establishment for such special work ; besides other new buildings it would entail a chemical laboratory, and there is hardly space for those at Greenwich. I believe also that it would cause too divided attention on the part of the Astronomer Royal, if he were called upon to personally superintend investigations in the physics of astronomy, although I think it would be very desirable that any new establishments, if they are to exist, should be affiliated to Greenwich."

Admiral Richards, late Hydrographer to the Admiralty, and a Visitor of the Royal Observatory, Greenwich, says :-

"If you are going permanently to establish physical observatories, I should prefer to see separate ones. I think that the physical work probably would be better separated from the Royal Observatory."

"You think that the two classes of observations are so distinct in character as to render that desirable?-OF course there is a certain amount of meteorology that must be observed at the astronomical observatory; but it need not be of any extended character."

A resolution in general accordance with the views ex pressed by Sir George Airy was transmitted to the Commission in July I 872 , by the President and Council of the Royal Astronomical Society. This resolution is in favour of the extension of the Royal Observatory at Greenwich and other existing Astronomical Observatories, and does 
not recommend the establishment of an independent Government observatory for the cultivation of astronomical physics in England.

In connection with some points on which differences of opinion have been expressed in this evidence, a paper was handed in by Col. Strange, consisting of questions addressed by him to Prof. Sir W. Thomson, Prof. Hilgard, the Secretary of the American National Academy of Sciences, and Prof. Balfour Stewart, and to M. Faye, the President of the French Academy of Science.

Col. Strange's questions were as follows :-

"I. Is the systematic study of the solar constitution likely to throw light on subjects of terrestrial physics, such as meteorology and magnetism?

"2. What means, at present known to science, are available for studying the sun?

"3. Do you consider that photography (one of the assumed means) will suffice for the purpose?

"4. Do you consider that the class of observations (defined in your answer to my question 2) are such as can be efficiently made in an observatory maintained by the State, or that any of them would be better left to the zeal of volunteer astronomers?

"5. Do you consider that it would be advantageous to carry on physico-astronomical researches on an extensive scale, and meridional observations, in one and the same observatory, under a single director?"

We regret that our space will not permit us to give the replies of these eminent men to Col. Strange's questions. They were, however, strongly in favour of the establishment of physical observatories on a footing quite distinct from existing meridional observatories, and equipped with the laboratories and workshops without which such institu. tions would be useless. We commend to all who are interested in this question the perusal of this correspondence, which is to be found as Appendix vii. to vol. ii. pp. 27-3I. Its value is enhanced by the fact that two of the writers, Prof. Hilgard and M. Faye, are distinguished foreign men of science.

\section{Evidence relating to Meteorology.}

Under this head a considerable amount of evidence was taken, particularly as to the constitution, objects, and results of the Meteorological Office.

This Office is under the management of the Meteorological Committee of the Royal Society, the functions of which are thus described in the report annually presented to Parliament :-

"The Meteorological Committee consists of Fellows of the Royal Society who were nominated by its President and Council, at the request of the Board of Trade, for the purpose of superintending the meteorological duties formerly undertaken by a Government Department, under the charge of Admiral Fitzroy.

"The Committee are credited with a sum of 10,0000 ?. voted annually in the Estimates, for the administration of which they are wholly responsible, and over which they are given the entire control.

"The meetings of the Committee are held once a fortnight, or oftener when necessary, when every subject on which action has to be taken by their executive officers receives their careful consideration. The duties of the Committee are onerous and entirely gratuitous; they were accepted and are very willingly performed by the members, on account of the earnest desire they severally feel for the improvement of meteorological science."

The position of the Committee is anomalous. In the words of the director of the Meteorological Office--
"The Government distinctly disclaims all connection with us, whilst the Royal Society equally disclaims all control over us, except merely the nomination of the members of the Committee."

"As a matter of fact, all that the Royal Society does is to nominate the members of the Committee?-That is all."

"Having so done, it ceases to have any control whatever, does it not?-Entirely."

"What is the precise relation between the Office and the Government? - That the Government gives a vote of 10,000l. every year, and that it calls for no account of this money excepting the account annually presented to Parliament."

"Who audits the accounts?-The members of the Committee. There is no formal audit, because, as the Government would not recognise any audit excepting its own, the Committee considered that it was not worth while paying an auditor if such audit would not be recognised, and, as a matter of fact, two of the members take the trouble of auditing the accounts every year."

"What, in your opinion, are the chief advantages and disadvantages of such an arrangement as compared with those of the direct management of the Office by the Government?-The chief advantage is the perfect freedom from political management. The risk in being connected with the Government is that if a new President of the Board of Trade comes, he may reverse the action of the preceding one. The existence of a scientific supervision for the Office is exceedingly important; it acts as an intermediate party between the public and the Office. I may mention a decided disadvantage which results from the Office not being connected with the Government, namely, the loss of prestige. The difficulty is, that if we are sending instruments by sea or by railroad, if we do not call them Government instruments we cannot get as much attention paid to them; and it is my opinion that we should get more co-operation from the merchant navy if we were an office of the Board of Trade. We should have more prestige as acting directly from the Government."

A very clear account of the objects which the Meteoro. logical Committee propose to themselves is given in the evidence of Major-General Strachey, one of the mem. bers :-

The Commissioners remark that it is admitted that the objects thus described do not exhaust the whole of meteorology, and that the Committee in their selection of these objects have been, to a great extent, guided by the proceedings of the Meteorological Department of the Board of Trade, which existed prior to, and which has been superseded by the Committee. Thus Major-General Strachey says :--

"The Committee is now in reality doing no more than continuing the exercise of certain functions which had, in the course of time, been thrown upon the Board of Trade by the position which that department occupies in connection with the public administration."

"Has the consequence been that the action of the Committee has been from the outset rather in a practical direction than in one of original research or scientific observation, properly so called? - I think distinctly that such is the case, and that it has necessarily followed from the position in which the Committee was placed. If a reference is made to the earlier papers, and to the report of the gentlemen on whose suggestions the present arrangements originated, there perhaps is an indication that they anticipated something more in the way of scientific research than has actually occurred; but the turn that things have taken seems to me the necessary result of the sort of duties that were put upon the Com- 
mittee under the essential condition that it had but a Iimited sum of money to spend."

"Have any results of scientific importance in your opinion been obtained by the action of the Committee ? In the direction of what one may call investigation of an absolutely scientific character, I should say none at all. Of course the observations that are made at the special observatories are valuable scientific information, and so far one has no right to say that scientific results have not been produced; but I do not think that these can properly be referred to as specific results of anything that the Committee has done. To the best of my belief there has been nothing undertaken in the way of original investigation into the specific physical causes of any of the phenomena which are recorded, nor any original research, properly so called, in relation to any of the several branches of meteorology. The Committee hardly has appliances at its command for any such investigations, and, the funds at its disposal being limited, it was hardly possible that it should attempt them. It is also no doubt quite true that the observations which are made at the seven observatories do not include any matters which are of great importance in physical science, and which would properly come within the range of meteorology."

"Are the funds at the disposal of the Committee in your opinion insufficient for doing anything more than has been actually done at present?-I should say distinctly that this is the case. The Committee has always considered that it is bound to attend primarily to the special objects before referred to, which were in a specific manner made over to it, and it finds that after this has been done there is no money left for other things."

Again, the same witness expressed a decided opinion that the State should do more for the promotion of meteorological science than it does at present, but entertains some doubt whether any increased duties could advantageously be allowed to devolve upon a body such as the Meteorological Committee.

The same view is expressed by Professor Balfour Stewart :-

"Would you orgarise the Meteorological Committee in any really different form to that which at present obtains?-I should be inclined to dispense with the Meteorological Committee altogether, and substitute a Meteorologist Royal, or whatever his appellation might be, a single official who should be responsible to the Government in the same way as the Astronomer Royal is responsible for his department. I do not see why the one department should be on one footing and the other department on a different footing. I think that there are grave disadvantages with a department administered by an unpaid committee."

"Would you appoint a Meteorologist Royal corresponding with the Astronomer Royal?-Yes, whatever the name might be; I should appoint an official very much corresponding to the Astronomer Royal, and responsible to the same extent. A board of visitors would not be objectionable, but the direction of an unpaid committee appears to me to be very objectionable."*

\section{Evidence relating to Tidal Observations.}

Evidence in reference to tidal observations has been placed before the Commission by Dr. Joule and Prof. Sir W. Thómson.

Dr. Joule is of opinion that-

"With regard to the sea level and the tides, although the laws with regard to the tides are pretty well known,

* The whole of the evidence, of which the above are curtailed extracts, eoincides with the trenchant remark of the Astronomer Royal in his last Repurt to the Board of Visitors that "The subject of Meteorology hardly deserves the name of a science." they ought to be continuously observed, if only for the purpose of registering the changes arising from the alteration of banks, depth of channels, \&c. Also with regard to the sea level, there have been reports from time to time with regard to the inroads of the sea on our coasts, but sufficient steps do not appear to have been taken to ascertain the facts in those cases. It seems to me very important to be acquainted with any alterations in the configuration of the earth which may be taking place, however minute those alterations may be."

Sir W. Thomson gives the following evidence on this point :-

"In addition to those institutions which you have recommended, you consider, do you not, that it would be advisable that the Government should undertake secular observations of the tides?-Yes, certainly, secular observations of the tides with accurate self-registering tide gauges, with the triple object of investigating the science of the tides, of perfecting our knowledge of the actual phenomena of the tides, both in respect to naviga. tion and as a branch of natural history, and, thirdly, with a view to ascertaining the clianges of the sea level from century to century."

"Is anything of the kind done at present?-There are several tide gauges, some of which have been carried on with great care, others with not sufficient care, and none with any security of permanence."

"Was not it in connection with the Ordnance Survey of Great Britain?-No sufficient steps have been taken to ascertain whether the sea level is changing relatively to the land in any part of this country."

The Commissioners state that the accurate reduction of tidal observations, without which, of course, they are useless, has not hitherto been undertaken by any department of the State, and we are indebted to the zeal of individuals for the results which have been obtained. The reductions are laborious, and require the employment of paid computers. A memorial from the British Association for the Advancement of Science to the Lords Commissioners of the Treasury, put in evidence by Sir William Thomson, shows the difficulty that has been felt in procuring the moderate sum required for the reductions, the amount asked for being only 150 .

The Lords Commissioners of the Treasury did not accede to the prayer of the memorial, so that at present there is no guarantee that the observations which have already been accumulated, and those which are still in progress, will ever be adequately discussed and utilised.

Evidence relating to the Extension of the Government Grant administered by the Royal Society.

The Commissioners remark: "The strong and concurrent evidence which we have received as to the usefulness of the Government grant, as at present administered by a Committee of the Royal Society, has led us to inquire whether this grant might not be advantageously extended; and the witnesses whom we have examined on this point are unanimous in expressing the opinion that great benefits might be expected from such an extension."

Prof. Owen, Mr. Spottiswoode, Prof. Grant, Mr. De la Rue, and Col. Strange are amongst those who gave evidence to the above effect. Lord Salisbury is also of opinion that the Government grant might be increased, in order to afford liberal assistance to "first-rate workers."

Evidence as to the Payment of Scientific Workers.

The Commissioners remark :-

"On this branch of our inquiry the evidence laid before 
us, both by statesmen and men of science, is to the same effect, and in favour of increased State aid. It has also especially been urged upon us, that to afford, by direct pecuniary aid, the means of livelihood to men of distinction in pure investigation would be a great advantage to science, as competent investigators would thus be enabled and encouraged to pursue a strictly scientific career."

Lord Salisbury is of opinion that the cause of science is hindered by the want of a sufficient career for scientific mon, giving the following statement of his reasons:-

"I am induced to think so, by noticing how very much more rapid the progress of research is where there is a commercial value attached to the results of it, than in other cases. The peculiar stimulus which has been given to elfctrical research, in the particular direction of those parts of it which concern the telegraph, is a very good instance in point, and the extent to which researches into organic chemistry have almost clustered themselves round the production of coal tar colours is another instance in point. And therefore it is difficult to avoid the conclusion that research is really hindered by the necessity under which those who are most competent to conduct it feel themselves, of providing for their own support by means of the talent and the knowledge which they possess."

With regard to the scale on which such remuneration or paynents for maintenance should be made, Lord Salisbury observes :-

"I should say, taking the parallel [that of certain offices in the Church], to which I have already alluded, that an income of about $1,000 \%$. or $1,500 \%$. a year would be the kind of income which would suffice for the purpose that I have in view."

And he would also add provision for retirement.

With reference to the safeguards against abuse which would be necessary, Lord Salisbury continues :-

". . . It would, for their [the investigators"] own interest, and to save them from invidious comments, be desirable to impose upon them the necessity of publishing, either in the form of books or in the form of lectures (but not sufficient in number really to impede their work), an account of the result of their labours during each successive year. Perhaps one or two stated lectures in the course of a year, to be delivered to University students, would be the best means of imposing upon them that test of industry."

Lord Derby takes the same view :-

"I think that, in one way or another, where you have a man of very great eminence as a scientific discoverer, it is unquestionably the duty of the State to provide him with means and leisure to carry on his work. Whether that is to be done by giving him an office under the British Museum, or in any similar institution, or whether it is to be done by simply granting him a pension in recognition of eminent scientific service, or in whatever other way it is done, it seems to me to be immaterial, but I ccrtainly consider that it is a very important part of the public duty, to relieve men who have shown an eminent capacity for original discovery and research from the necessity of engaging in a lower kind of work as a means of livelihood.". . .

Sir $W$. Thomson, in a reply to which we have already referred, stated his opinion on this point as follows :-

"That men should be enabled to live on scientific research is a matter of most immediate consequence to the honour and welfare of this country. At present a man cannot live on scientific research. If he aspires to devote himself to it he must cast about for a means of supporting himself, and the only generally accepted possibility of being able to support himself is by teaching, and to secure even a very small income, barely sufficient to live upon, by teaching, involves the expenditure of almost his whole time upon it in most situations, so that at present it is really only in intervals of hard work in professions that men not of independent means in this country can apply themselves at all to scientific research." . . .

Prof. Henry, the distinguished director of the Smithsonian Institution in the United States, who was good enough to appear before the Commission when he was in this country, gave the following emphatic evidence in the same direction :-

"My idea would be that if the funds were sufficient, and men could be found capable of advancino science, they should be consecrated to science, and be provided with the means of living above all care for physical wants, and supplied with all the implements necessary to investigation."

Prof. Balfour Stewart, after referring to the instances of wealthy persons who undertake scientific research in this country, points out that the number of those so circumstariced is very small in comparison with the number of able men who are willing to give their time and capacities to observations and research. He goes on to say that able men, and men competent to conduct research, suffer in this country from not having sufficient means at their disposal to proceed as they would like to do.

"Do you anticipate, then, that if there were any intelligent centre for the distribution of a sufficient fund to persons having the requisite capacities for observation and research, but not having the means, the distribution of such a fund would have any benumbing infuence upon original observation and research?-No, I should think quite the contrary ; it would encourage it very much."

Mr. Gore also advocates the enlargement of the present system.

". . . I I should strongly advocate that the present system should be enlarged, so that the investigators should not inerely be reimbursed for all that they have expended, but also paid in some measure for their time and labour, because each investigator has to give up a profitable employment in order to find the time."

He then gives his own personal experience, which probably resembles that of many of those who, without private fortune, engage in pure research.

"I refuse a great many engagements in analyses and other scientific matters for the manufacturers who come to me. ... I gave up some pupils a short time agó to enable me to have more time for original investigation."

Dr. Joule, Dr. Siemens, Mr. De la Rue, and other scientific authorities testify to the same effect, and urge the adoption of some form of remuneration for valuable work done, as a measure not merely just to the individual, but serviceable to the State by the encouragement it would afford to those able men of small means, who abound in this country, to engage in original researches of great importance to the community.

(To be continued.)

\section{THE IRISH FISHERIES}

Report of the Inspectors of Irish Fisheries on the Sea and Inland Fisheries of Ireland for I874. Presented to both Houses of Parliament. (Dublin: Alex. Thom, 1875.)

DRING the last few years increased attention has been paid to the vast stores of food, which this country possesses, in the fish frequenting its inland. 